\title{
A Convivência de Diferentes Culturas Políticas no Espaço Metropolitano
}

Léa Guimarães Souki ${ }^{1}$

Resumo: O objetivo deste artigo é analisar as articulações da cultura política tradicional, entendida como "Cultura Cívica", e da "Nova Cultura Política" (NCP), enquanto conviventes no mesmo espaço metropolitano. A questão central do trabalho é saber se faz sentido, em um país com pouco tempo de existência da democracia, e com as características do Brasil, elaborar um conceito para apreender a NCP que seja adaptado às nossas idiossincrasias. Esse esforço envolverá uma discussão teórica e metodológica sobre o conceito de cultura política, assim como sobre a adequação da nova concepção de NCP a uma cultura metropolitana de tradição democrática recente.

Palavras-chave: Cultura Cívica, Nova Cultura Política, Metrópole, Democracia Recente, Cultura Metropolitana.

A obra Cultura Cívica, de Almond e Verba (1963), iniciou uma tradição empírica nas ciências sociais que se firmou e ampliou para além a próprio conceito de cultura política. Essa tradição, iniciada na década de 1970, significou um novo marco para a pesquisa social e um significativo aperfeiçoamento metodológico no que refere à pesquisa empírica. Por outro lado, a nova tradição também tem sido alvo de crítica pela ausência de aspectos mais filosóficos e epistemológicos, que a obra não teria contemplado (LESSA, 2002). Outro conjunto de críticas relaciona-se ao suposto etnocentrismo nela contido, isso porque, ao se basear no modelo das sociedades anglo-saxônicas, enfatiza a estabilidade política como fator fundamental da "cultura cívica", entendida como suporte da democracia².

O conceito de cultura cívica, da maneira como o formulou Almond e Verba, supõe a existência de certos padrões de crenças e de comportamentos políticos e a possibilidade de conhecê-los através de certo tipo de pesquisa empírica. Os autores afirmam, também, existir uma congruência entre a estrutura das instituições democráticas e os padrões de cultura democrática. Assim entendido, a uma cultura política súdita corresponderia uma estrutura autoritária e centralizada, enquanto a uma cultura participativa corresponderia uma estrutura democrática. Ainda que a pesquisa sobre valores que favorecem a democracia tenha sido refeita duas décadas depois por Almond e Verba (1989), ocasião em que acrescentaram aspectos de natureza institucional para explicar as
Recebido:

06.11.10

Aprovado: 10.04.12

1. Doutora em Sociologia Política pela UNB; Professora Titular da PUC-MG E-mail: leaguim@ terra.com.br

2. No arcabouço conceitual de Almond e Verba (1963), a ideia de estabilidade política é fundamental. Como as forças políticas de uma sociedade ativa, no caso de uma cultura participativa plena, poderiam ocasionar pressões em excesso ao sistema, comprometendo seu funcionamento; sob esse ponto de vista, torna-se importante a ideia de subculturas ou culturas mistas. Essas orientações, se equilibradas, são capazes de fomentar a estabilidade do sistema político, na medida em contêm: orientações ativas e orientações passivas; orientações instrumentais e afetivas; consenso e dissenso. A importância da estabilidade como um ponto fundamental do conceito está bem desenvolvida em Meyenberg (2006). 
possibilidades de algumas culturas favorecerem mais a democracia que outras, é sua obra inicial que tem sido considerada como referência no desenvolvimento das ciências sociais enquanto marco da pesquisa empírica. Quanto ao papel da dimensão institucional, é Putnam (1996) quem marca os estudos sobre o papel das instituições necessárias ao ambiente democrático. Sobre esse aspecto, ao analisar o desempenho institucional dos governos regionais da Itália, a partir da reforma descentralizadora ocorrida na década de 1970, sua pesquisa pode ser entendida como um desdobramento da análise da cultura cívica. 0 autor sustenta que o desempenho institucional democrático deve ser sensível e eficaz e o associa ao ambiente cívico, em sua pesquisa desenvolvida ao longo de vinte anos.

Sob o escopo da abordagem clássica de Almond e Verba, o comportamento político pode ser conhecido através de seus aspectos relacionados à cognição, à afetividade e ao julgamento. Essa forma de compreensão do comportamento político fundamenta-se em certos princípios, os quais sucintamente serão expostos a seguir.

A caracterização dos tipos de cultura política, conforme formulada por Almond e Verba, baseou-se no estudo comparado de cinco países - Estados Unidos, Reino Unido, México, Itália e Alemanha Ocidental - e refere-se a orientações especificamente políticas: as posturas relativas ao sistema político e seus diferentes elementos, e os aspectos pertinentes à função do próprio sujeito dentro do sistema. Dessa forma, a cultura política de uma nação consiste na distribuição particular, entre seus membros, das pautas de orientação para objetos políticos.

A orientação política que os indivíduos podem assumir em relação aos fatos e aos objetos sociais podem ser de três tipos. O primeiro deles refere-se aos conhecimentos e crenças acerca do sistema político, de seus papéis e dos responsáveis pelos mesmos, tanto em seus aspectos políticos ativos (os inputs) quanto nos administrativos (os outputs). A esse tipo deram o nome de orientação cognitiva. O segundo tipo, que se refere aos sentimentos acerca do sistema político, de suas funções, do pessoal envolvido e dos ganhos existentes, é denominado de orientação afetiva. Já o terceiro tipo, a orientação avaliativa, diz respeito aos juízos e opiniões sobre objetos políticos que envolvem a combinação de critérios de valor com a informação e os sentimentos.

\section{Alguns Aspectos Problemáticos do Conceito de Cultura Política}

Antes de prosseguir nas definições do que aqui se propõe analisar, a chamada cultura política metropolitana, fazem-se necessárias algumas considerações sobre o debate em torno do conceito de cultura política, assim como às 
críticas recebidas pelo mesmo. O estudo de Almond e Verba tem sido visto como um marco no desenvolvimento das ciências sociais em dois aspectos: um primeiro, relativo ao objeto, e um segundo, pertinente ao desenvolvimento da metodologia de estudos empíricos em geral. Um de seus pressupostos é que as crenças e valores dos indivíduos têm uma relação bastante clara com a maior ou menor adesão à democracia, assim como com a capacidade de promovê-la e sustentá-la. Outra ideia a ele subjacente é a de que a cultura conteria certos padrões, regulares, que poderiam ser conhecidos e verificados por meio da manifestação dos indivíduos, evidenciada especialmente através de entrevistas e questionários. Na esteira desses pressupostos, proliferaram tanto as pesquisas empíricas quanto as informações disponíveis sobre o tema, a ponto de Przeworski, Cheibub e Limongi (2003, p. 13) afirmarem que essa tradição gerou uma nova indústria. Outra suposição de Almond e Verba é o fato de que haveria padrões, mais ou menos regulares, de crenças e valores que seriam mais compatíveis com regimes democráticos do que outros. Esse aspecto tem sido fonte de persistentes debates, dos quais destacaremos as questões mais relevantes, cujo conhecimento mostra-se imprescindível a uma reflexão sobre o tema.

Um dos pontos críticos do conceito reside no fato de que, apesar dos inúmeros dados apresentados, não é claro se os valores verificados são o efeito ou a causa das mudanças políticas em questão. Maravall (1995), por exemplo, ao discutir a relação entre política, valores e economia, nas transições aos regimes democráticos, argumenta que muitas democracias foram precedidas pelo aumento do número de democratas. Nesse caso, não foram as experiências democráticas que transformaram os valores e atitudes, uma vez que havia democratas antes mesmo de haver democracia. $O$ debate aparece também, incitado por Przeworski, Cheibub e Limongi (2003), em torno do "culturalismo", quando se discute a difusa e complexa relação entre cultura e política e a capacidade da primeira explicar a emergência e a persistência da democracia. Os autores sustentam que os fatores econômicos são suficientes para explicar essa relação sem que seja necessário recorrer à cultura. Resumidamente, poder-se-ia dizer que argumentam no seguinte sentido: sendo problemática a relação entre cultura e política, é ainda mais complexo estabelecer uma relação de causalidade entre esses conteúdos. Segundo eles, clássicos como Montesquieu, Stuart Mill e Adam Smith, tendo reconhecido a importância da cultura para a democracia, teriam sido ambíguos no que diz respeito ao estabelecimento de uma cadeia da causalidade que levaria às mudanças da humanidade de um estágio ao outro. Os autores constroem sua crítica ao culturalismo em torno da ambiguidade nas explicações dos nexos causais entre cultura e política na literatura: "Seria o progresso material o gerador das mudanças na cultura e nas instituições políticas, ou seriam as transformações culturais que fariam avançar o progresso material e as formas de governo?" (PRZEWORSKI, CHEIBUB \& LIMONGI, 2003, p. 12-13). 
Se a cultura importa seria, pois, necessário estabelecer como importa e sob quais condições, e ainda quais seriam os aspectos mais significativos no que se refere a determinadas orientações políticas.

A Cultura Cívica de Almond e Verba teria sido uma tentativa de responder a esta questão - segundo os autores, a cultura forneceria a base psicológica da democracia. Eles observaram que os aspectos tecnológicos eram mais facilmente assimiláveis que a cultura política ocidental e que, embora a economia fosse fundamental, não era suficiente para promover a democracia, sendo necessária uma base psicológica fornecida pela cultura.

Muito da perspectiva "culturalista", no entender dos autores em discussão, basear-se-ia em um argumento ex-post, fundamentado na ideia de que a democracia tem como requisito um tipo específico de cultura política, alcançado por determinados países. Essa postura estaria calcada na leitura e descrição do caso dos países que lograram chegar primeiro a seus resultados, dentre os quais os mais emblemáticos seriam, em primeiro lugar, os Estados Unidos e, em segundo, a Inglaterra. O referido modelo suporia, portanto, que quanto maior a proximidade com esses dois casos, mais democrática seria a cultura política de um país.

No bojo dos questionamentos à visão culturalista, os críticos em questão veem o desdobramento e a validação desse enfoque nos estudos de Inglehart (1977) e seus colaboradores, para quem a cultura cívica estaria sustentada em três indicadores, confiança interpessoal, satisfação vital e apoio à mudança revolucionária. Baseando-se em suas pesquisas empíricas, segundo Przeworski, Cheibub e Limongi (2003, p. 14), "Inglehart e seus colaboradores descobriram que (empiricamente) essas variáveis, quando tomadas em conjunto, relacionam-se estatisticamente com o número de anos contínuos de democracia entre 1900 e 1980 e entre 1920 e 1995, numa amostra de 24 países". Recolocando a questão inicial sobre a direção da causalidade, Inglehart consideraria preferencialmente os atributos das democracias duradouras concluindo, para a América Latina, que é a estabilidade que gera a cultura democrática.

No artigo "Dormindo com o inimigo", Feres e Eisenberg (2006) procuram discutir, de maneira bastante consequente, a ideia de "confiança" presente nos trabalhos de Inglehart, entendendo como muito genérica a pergunta feita em seus surveys: "Em geral você confia nas pessoas?". Os autores questionam até que ponto essa pergunta não teria sido formulada para um tipo específico de cultura, assim como que tipo de confiança ela poderia medir - seria a ideia de confiança universalmente compartilhada?

Em seu estudo, Inglehart conclui ainda que as culturas protestantes teriam 
uma tendência maior a estabelecer relações de confiança, aspecto também questionado por Przeworski, Cheibub e Limongi, para quem os estudos empíricos não mostram uma relação clara entre política e religião - estas seriam espécies de invólucros, cujos valores a ser enfatizados dependeriam de definições estratégicas feitas exteriormente a elas ${ }^{3}$.

Os limites do conceito de confiança também foram tratados por Reis (2003) no contexto da crítica à noção de capital social desenvolvida por Putnam (1996). Segundo o autor, a noção de confiança ganha, no trabalho de Putnam, um enorme atributo na lógica de seu arcabouço conceitual, a ponto mesmo de se confundir com o capital social. Para o autor, a "confiança apresenta-se como uma caixapreta conceitual, passível de variadas interpretações". Ora é entendida como atributo individual, ora como atributo relacional (confiança da rede, formada entre pessoas que se associam). Assim, a concepção de confiança teria que dar conta de um intrincado sistema de correlações que, ainda que tratado por Putnam de maneira sistemática e rigorosa, convive com um déficit conceitual. No último capítulo do livro, a "confiança" passa a ser quase a explicação de tudo.

As reflexões de Feres e Eisenberg representam um importante passo nessa discussão. O alvo de sua crítica ao conceito de confiança se respalda na pesquisa conduzida por Inglehart em um survey mundial, em 43 países, entre 1990 e 1993. Nesse survey, o Brasil foi o país que obteve o resultado mais baixo (7\%) diante da seguinte pergunta: "Em geral, você diria que a maioria das pessoas é confiável ou que se deve ser precavido ao lidar com elas?". Feres e Eisenberg se propõem, assim, a discutir o que eles chamam de déficit conceitual e, para isso, analisam o peso dado por Ingelhart à religião na explicação da democracia e de sua estabilidade. No bojo desse argumento, o protestantismo seria tratado como a razão última - desconsiderando-se a explicação weberiana da secularização do mundo moderno - da democracia da qual fariam parte os Estados Unidos, os países anglo-saxões e as nações germânicas protestantes. Ao resto do mundo, caberia a cultura tradicional, presumivelmente não cívica.

Após meticulosa análise semântica das duas raízes do conceito de confiança, uma latina (fides) e outra inglesa (trust), os autores pontuam sobre a delimitação e a especificação do sentido da palavra. Em suas origens históricas, uma estaria mais condicionada e delimitada às relações comerciais, ao passo que a outra vincular-se-ia às relações mais pessoais e afetivas. Até que ponto a noção de "confiança", na pergunta de Inglehart, evocaria relações contratuais delimitadas ou relações afetivas e pessoais? Isso posto, deduz-se que as pessoas entenderiam e responderiam à pergunta conforme sua tradição, de forma que os resultados do survey poderiam levar a conclusões enviesadas ${ }^{4}$.

Segundo os críticos, na tentativa de qualificar e delimitar o sentido da
3. Embora incorrendo em certo simplismo, mas apenas a título de alerta sobre a complexidade do tema, poder-seia, resumidamente, dizer que, segundo Przeworski, Cheibub e Limongi (2003), os princípios doutrinários das religiões - confucionismo, islamismo, catolicismo e protestantismo -, por si, não guardariam nenhuma relação tácita com a democracia, seja para sustentá-la, seja para impedi-la. Consideram-se alguns elementos a serem lembrados como: a importância dada por Tocqueville ao catolicismo para - republicanismo americano; o que Lipset considera, a partir de Weber, da importância do protestantismo concatenado com uma série de fatores que geraram uma mescla única no noroeste europeu; sobre o confucionismo, aspectos doutrinários favoráveis ao governo limitado; no islamismo, as interpretações doutrinárias, a cargo de qualquer mulçumano capaz e qualificado, estariam servindo para justificar arranjos políticos inteiramente diferentes.

4. Em outras palavras, ao serem perguntados "'generally speaking, would you say that most people can be trusted...?', os falantes de 
língua inglesa podem ter entendido que a expressão 'most people can be trusted?' se refere às pessoas sobre as quais a confiança pessoal pode ser depositada, isto é, aquelas pessoas que são próximas (...). Por outro lado, falantes de línguas neolatinas teriam mais dificuldade em depositar 'confiança' em 'pessoas em geral', visto que as condições da relação de confiança não são dadas pelo enunciado da pergunta. Inglehart poderia ter refinado mais sua ferramenta de pesquisa, incluindo a pergunta 'do you generally trust 'strangers'"? (FERES \& EINSEBERG, 2006, p. 468 , grifo nosso). "confiança" e de adequá-lo à teoria democrática moderna, os autores propõem a distinção entre confiança interpessoal e confiança institucional. Como confiança interpessoal, Feres e Eisenberg entendem: "é a expectativa depositada em um estranho de que este aja de maneira cooperativa, ou, pelo menos, não danosa, em relação ao depositante". Como confiança em instituições, definem: "é a expectativa de ação reparatória ou punitiva por parte dos poderes estabelecidos contra todos aqueles que violarem os preceitos da lei". Voltando à questão da importância da confiança e de seu papel na teoria democrática para as sociedades contemporâneas, os autores acrescentam a dimensão da justiça distributiva à ideia de "confiança política", entendida como "a confiança que o corpo de cidadãos deposita nas instituições responsáveis pelo reconhecimento, participação e distribuição de riquezas". Enfim, concluem que uma pergunta tão genérica e simplificada não daria conta da complexidade da noção de confiança na teoria democrática moderna.

Finalmente, a crítica teórica e metodológica mais vigorosa vem de J. Johnson (2004), segundo quem, a despeito do acúmulo de informações e correlações que essa tradição vem produzindo, ela não teria conseguido estabelecer relações explicativas entre cultura e política. O autor evoca a importância dessa relação na obra de Geertz e argumenta no sentido de a tradição da cultura política não ter acompanhado os avanços da vertente interpretativa da antropologia, de inspiração weberiana, na qual Geertz se insere. Para ele, haveria um déficit interpretativo no que se refere aos símbolos e práticas sociais "que incorporam os significados através do qual os homens dão forma às suas experiências", uma vez que a política é "uma das principais arenas em que tais estruturas se desdobram publicamente" (JONHSON, 2004, p. 136). Enfim, Johnson entende como déficit a incapacidade que apresenta a cultura política para deslindar as ligações causais entre cultura política, desenvolvimento econômico e democracia.

Consideradas as questões relacionadas aos limites da ideia de cultura política, com ênfase especial ao debate atual sobre a noção de "confiança", poder-se-ia questionar até que ponto essa discussão pode ser útil à definição da Nova Cultura Política e, em sequência, ao esforço de definir uma Cultura Política Metropolitana. Não há como resolver as grandes questões colocadas no debate atual; entretanto, desconhecê-las seria engessar um conceito que se propõe a transitar em países diferentes e em culturas diversas e que, por isso, estará sujeito a várias críticas, aqui tratadas como uma espécie de "estado da arte".

\section{Uma Nova Cultura Política?}

A partir dos anos 1980, com a crescente efetivação do padrão multicultural, 
a complexificação social e as novas formas de participação, os modelos usuais de comportamento político passaram a mostrar efeitos novos e contraditórios em relação aos até então formulados. Os novos enfoques começaram a questionar a existência de direções e padrões uniformes que indicassem o comportamento político adequado à democracia, tomando como ponto de partida a complexidade das sociedades e o surgimento de uma pluralidade de interesses que competiam entre si na arena política. Uma das tentativas mais reconhecidas de reconstruir o modelo da Cultura Política, no bojo da tradição iniciada por Almond e Verba, encontra-se no livro de Ronald Inglehart A Revolução Silenciosa (1977), que pesquisa valores em seis países. O autor argumenta que o crescimento econômico sustentável e a relativa paz mundial - observada no Ocidente desde 1945 - conectam-se com novas formas de atividade política e novas identidades, baseadas em valores pós-materialistas. Uma vez que os indivíduos se encontraram em certo nível de segurança física e material, deslocaram suas preocupações políticas para âmbitos diferentes do mero bem-estar básico. Se na Cultura Política tradicional os indivíduos demonstram uma postura de aceitação da atividade política como algo manejado pela elite, na nova maneira de interpretar as mudanças os indivíduos colocam-se em atividades que questionam o trabalho das elites e se propõem novos desafios políticos. A análise de Inglehart apresenta uma clara tendência em entender as transformações a partir da visão de países afluentes e que não viveram ditaduras. Contudo, sua abordagem terá um importante papel na conceituação do que, modernamente, se chama de Nova Cultura Política.

No bojo do questionamento dos padrões da Cultura Cívica, os trabalhos de T. N. Clark (2002) avançou no sentido de traçar matizes para explicar o que ele denomina de "Nova Cultura Política". Essa abordagem, Nova Cultura Política, procura compreender uma espécie de desalinhamento na organização do comportamento político que, longe de ser entendido - conforme ocorreria convencionalmente - como um esfacelamento das orientações políticas, é agora analisado tal qual algo novo. A Nova Cultura Política, NCP, compreendida como uma nova orientação cognitiva, afetiva e avaliativa em relação a um sistema de objetos e processos sociais, foi caracterizada por Clark basicamente a partir dos seguintes conteúdos:

1) uma redefinição do contínuo esquerda e direita;

2) separação de questões sociais e financeiras, isto é, as atitudes em relação às questões sociais não são derivadas das atitudes em relação às questões financeiras;

3) os problemas sociais se tornaram muito mais importantes do que os econômicos e financeiros; 
4) ascensão do mercado e do individualismo social;

5) questionamento do Estado de Bem-Estar Social;

6) promoção das questões políticas e expansão da participação cidadã, acompanhada do declínio das organizações políticas hierárquicas, como os partidos e sindicatos;

7) essas orientações da NCP estariam mais difundidas entre os jovens e entre os indivíduos e sociedades mais formalmente educadas e afluentes.

Uma das novidades compreendidas nesse enfoque estaria na coexistência de posições aparentemente contraditórias entre si e aparentemente contraditórias com a democracia, conforme os parâmetros da Cultura Cívica.

Estamos nos referindo, aqui, a atitudes, à primeira vista, entendidas como despolitizadas e apáticas e que, contudo, no novo marco conceitual, ganham outros sentidos. A tudo isso se deve acrescentar que as características da NCP estariam presentes, especialmente, no espaço metropolitano (AZEVEDO, SANTOS JÚNIOR \& RIBEIRO, 2010; CABRAL, 2003, 2009).

Foi Cabral quem primeiro conduziu os estudos da NCP para o recorte metropolitano. No Brasil, essa vertente de pesquisa tem sido seguida pelos pesquisadores do Instituto de Pesquisa e Planejamento Urbano e Regional, da Universidade Federal do Rio de Janeiro (IPPUR/UFRJ), através de estudos empíricos em seis regiões metropolitanas (RMs) do Brasil, em que se exploram e medem a dimensão política da cidadania, a relação do cidadão com o Estado, a socialização política e as novas formas de associativismo.

\section{A Nova Cultura Política e a Cultura Política Brasileira}

Supondo que haja uma mudança nos padrões convencionais da cultura democrática, em que medida a Nova Cultura Política, NCP, seria capaz de explicar as supostas mudanças no comportamento político dos brasileiros? O que aqui se sustenta é que, em se tratando de Brasil, o primeiro ponto a ser considerado é a convivência de várias culturas políticas. É necessário ressaltar, ainda, a complexidade dessas conexões e o fato de que, ao se mesclarem aos novos padrões da NCP, comumente associados à globalização e à desregulamentação produtiva, elas se tornam ainda mais complexas. Em segundo lugar, é preciso considerar que o Brasil é uma democracia jovem, que não viveu a experiência das lutas sociais nos mesmos padrões que as culturas centrais, onde o conceito de NCP foi gerado. 
Entre as inúmeras contribuições dadas por Edson Nunes, em seu livro A gramática política do Brasil (1999), merece destaque a ideia de que distintas gramáticas - o autor refere-se à relação da sociedade com o Estado - convivem no Brasil. Se o "universalismo de procedimentos" está crescendo no país, também podem estar na mesma situação o "clientelismo", o "corporativismo" ou o "insulamento burocrático". O autor mostra como, em determinados momentos, a implantação de uma nova gramática não inibiu um padrão anteriormente instalado. Ainda que a ideia de convivência possa parecer simples, coube a Nunes construir uma argumentação bem articulada e historicamente embasada dessa convivência, e que será útil à nossa discussão.

O conceito de NCP foi cunhado em países nos quais a cultura democrática já se havia estabelecido. Mesmo aqueles que passaram por interrupções ditatoriais - como os fascistas e parafascistas - já haviam vivenciado lutas sociais intensas. Portanto, nesses e naqueles países, o conceito de Nova Cultura Política corresponde à ruptura, mais ou menos alternativa, de um padrão anterior cuja história foi longa e, na maioria deles, difundida nas várias camadas da sociedade. Mesmo os países que estiveram fora da democracia - as chamadas "relíquias bárbaras do sul da Europa" (WHITEHEAD, 1988) -, quando de sua democratização, foram capazes, em diferentes medidas, de se adaptar a uma Europa moderna e corporativa, bastante diversa do padrão de lutas de classes que, em quase todos eles, havia sido cenário de sua entrada em regimes ditatoriais.

Aqui se sustenta que, quando se pensa a Nova Cultura Política, no Brasil, há que se considerar o fato de se tratar de uma democracia recente, em que, portanto, os padrões de cultura democrática, aqui entendida como "cultura cívica" tradicional, também são novos, assim como a própria ideia de NCP. Depois de quanto tempo se pode falar em uma democracia consolidada? Existiria um momento no qual se poderia afirmar a consolidação dos valores democráticos? Essa discussão tem sido contemplada por vários autores. Alguns definem o marco da consolidação democrática predominantemente pela questão eleitoral. Para esses, a consolidação poderia ser definida após a primeira eleição competitiva ou a primeira alternância de poder (LIJPHART, 2003; O'DONNELL, 1988). Outros autores discutem em que medida o efeito do passar do tempo sobre as culturas poderia favorecer o estabelecimento de valores democráticos que mantivessem uma "legitimidade autônoma", capaz de sobreviver às crises econômicas (MARAVALL, 1995; DAHL, 1989).

Em se tratando de uma democracia recente como o Brasil, não há como negar a transitoriedade da consolidação democrática, ainda que, a cada pleito, ocorra de forma incremental e pré-reflexiva um aumento da legitimidade lato senso da democracia ${ }^{5}$. Nesse ponto, torna-se interessante a pergunta de J. M. Maravall (1995): "É possível democracia sem democratas"? Isto é, pode a democracia
5. Pode-se partir da hipótese de que temos, concomitantemente, dois processos em ação; enquanto as eleições, realizadas operacionalmente, com alto grau de lisura e competência técnica, tenderiam a aumentar, paulatinamente, a institucionalização do sistema representativo, os chamados "escândalos políticos", mostrando o alto nível de corrupção de governantes e políticos nos três níveis de governo, funcionariam como elementos de descrença no sistema político vigente, especialmente entre os setores de maior escolaridade ou cultura cívica, uma vez que a maioria dos setores populares comunga o mito em situação oposta à dos Estados Unidos - de que se deve esperar que o chamado "homem público" aproveitese de sua posição para angariar, prioritariamente, benefícios pessoais. 
se consolidar apenas através de instituições virtuosas sem indivíduos que não a conheçam, não a valorizem e não a compreendam? Segundo o autor, não existe clareza nos estudos sobre a consolidação democrática e sobre o fato de serem os valores efeitos ou causas das mudanças democráticas. Em muitos casos, antes da queda das ditaduras, já existiam defensores de valores democráticos - como vimos, há casos em que as "democracias foram precedidas do aumento do número de democratas". Por outro lado, sabe-se que os valores mudam conforme as circunstâncias, ainda que de maneira lenta e nem sempre consciente, e a Cultura Cívica, não sendo uma condição prévia para a democracia, pode também ser o resultado do funcionamento prolongado de instituições que criam valores e crenças democráticas. A isso se acrescente a consideração de que haveria indícios de que a percepção dos cidadãos sobre a política varia conforme as condições da economia, especialmente quando os valores democráticos não estão, ainda, consolidados. Nesses casos, tais valores não desfrutariam de uma "legitimidade autônoma", embora já se pudesse falar de regime democrático.

Para Maravall, em se tratando de mudança política, apesar do grande volume de informações sobre distribuições de valores e atitudes políticas nas novas democracias, muitas questões ainda persistem. Não existem repostas claras para perguntas como: "Qual o peso do passado na configuração da cultura política da democracia? Até que ponto os valores democráticos já se expandiam na ditadura? Em que medida o mundo subjetivo dos cidadãos pode ser afetado pelas novas experiências democráticas"? Nenhuma dessas questões será aqui resolvida, mas acredita-se que elas não podem ser desconsideradas ao se tratar de padrões de cultura política em mudança em uma democracia jovem.

Voltemos ao cenário brasileiro de convivência entre distintas culturas políticas. Para esse contexto, a reflexão de Carvalho (1996) sobre um cenário de transitoriedade da cultura política - relatada no centro urbano mais importante do Brasil, o Rio de Janeiro do início do século XX - será ilustrativa. Trata-se da passagem da "cultura paroquial" à "cultura súdita", momento em que a população toma conhecimento do Estado por meio da obrigatoriedade do registro civil, da vacinação obrigatória e do recrutamento militar. O ponto de interesse aqui é o fato de que, no maior centro urbano do país, a cultura política ainda era, predominantemente, paroquial. Isso significa que os cidadãos não tinham noção da diferenciação das instâncias de poder; que a autoridade estava condensada, sem distinção de competências específicas; que existia uma ideia difusa do poder. Quando a população toma consciência do Estado - no caso relatado por Carvalho, sob sua forma mais coercitiva -, ela passa a entender a relação de mando e obediência e a distinguir diferentes instâncias de poder que podem coagi-la. Daí a passagem para o início da cultura súdita. Quanto à passagem para a cultura participativa, esta tem sido objeto de inúmeros estudos, ocupando 
nos últimos trinta anos, em grande medida, a agenda das ciências sociais no Brasil.

\section{A Articulação de Diferentes Culturas sob o Recorte Metropolitano}

Retomando a ideia da convivência de várias culturas e dessas com a Nova Cultura Política, como já se mencionou, seria o recorte metropolitano o lugar por excelência no qual se encontra revelada a complexidade das questões colocadas (CABRAL, 2009; AZEVEDO, SANTOS JÚNIOR RIBEIRO, 2010).

Sabemos que, quando um termo é usado para falar sobre mais de uma coisa, ele perde em precisão e se presta a confusões que ultrapassam questões semânticas. Do que se trata o "metropolitano" na Nova Cultura Política, cunhada por Clark e utilizada por Cabral? Estaríamos falando da mesma coisa, no Brasil, quando nos referimos à região metropolitana? Se considerarmos o caso de Portugal, a metrópole europeia historicamente mais próxima dos brasileiros, Cabral (2003) nos adverte que não está falando de capital, senão de metrópole. Em seu trabalho mais recente (CABRAL, 2009), o autor considera Lisboa como uma metrópole europeia na medida em que apresenta características específicas de composição demográfica - a presença de nova burguesia, do trabalho assalariado e de estrangeiros. Lisboa, ademais dessas características, guardaria ainda uma cultura mais laica e mais republicana que o resto do país.

Por seu turno, já se acumulou muita informação sobre a criação das regiões metropolitanas no Brasil - que se deu no período militar, no bojo das reformas racionalizantes -, assim como sobre sua expansão posterior (AZEVEDO, SANTOS JÚNIOR \& RIBEIRO, 2010; AZEVEDO \& MARES GUIA, 2010; MACHADO, 2009; ROCHA \& FARIA, 2010). Sob esse recorte institucional e administrativo criado nos anos 1970, tem cabido continuadamente o acoplamento de vários municípios marcadamente rurais ou com distintos padrões demográficos, formando redes com variados graus de coesão e acentuadamente assimétricas em seu interior. Algumas regiões metropolitanas, por diferentes motivos, incorporaram novos municípios através de critérios variados. Em alguns Estados, as regiões metropolitanas nascem e se proliferam - como no caso de Santa Catarina, em que chegam a existir 8 regiões metropolitanas, num estado em que a população é de 6 milhões de habitantes e onde se pode, contudo, contar uma metrópole (Florianópolis). Com isso, se quer afirmar que região metropolitana, no Brasil, não apresenta o conteúdo de metrópole conforme o entendimento de Cabral (2009) - lugar em que se prolifera a cultura laica e republicana, cidade que é muito mais que uma capital, mas o centro irradiador de uma cultura de padrões cosmopolitas. 
6. O Observatório das Metrópoles é um amplo grupo que funciona em rede, reunindo pesquisadores de instituições dos campos universitário, governamental e não governamental. Criado em 1995, o Observatório se constitui em um instrumento sistemático de estudo, pesquisa e difusão de conhecimentos, voltados para a promoção da cidadania na cidade. As equipes, reunidas em núcleos, vêm trabalhando sobre onze metrópoles e uma aglomeração urbana, identificando tendências convergentes ou divergentes entre as metrópoles, geradas pelos efeitos das transformações econômicas, sociais, institucionais e tecnológicas dos últimos vinte anos.

7. O Observatório das Metrópoles, o IPPUR/UFRJ e o Instituto de Ciências Sociais da Universidade de Lisboa (ICS-UL) vêm desenvolvendo um projeto comparativo sobre a análise das atitudes sociais de brasileiros e portugueses no marco das redes do Internacional Survey Research Programme (ISRP) e da European Social Survey (ESS). No Brasil, o projeto conta também com a participação do Instituto Universitário de Pesquisas do Rio de Janeiro (IUPERJ).
No Brasil, sendo a região metropolitana, também, um recorte de unidades territoriais administrativamente estabelecidas para objetivos relacionados a serviços comuns, ela reflete, além da cultura urbana, outro tipo de aglomerado urbano que nem sempre tem, estritamente, as características sociológicas da vida citadina.

Portanto, em se tratando de Brasil, embora nas grandes cidades se encontrem as características do urbanismo, a cultura metropolitana guarda padrões caleidoscópicos que mesclam culturas paroquiais e súditas em convívio com a vida urbana metropolitana mais participativa. Se considerarmos essas diferenças na ideia de metrópole nos países europeus e nos Estados Unidos, onde nasceu o conceito de Nova Cultura Política, e o recorte administrativo e político de regiões metropolitanas no Brasil, há que se levar em conta que nem sempre se está abordando a mesma coisa. A preocupação com a singularidade do recorte metropolitano no Brasil leva-nos a considerar que a utilização do conceito de Nova Cultura Política inspira cuidados, uma vez que abarca uma suposta cultura política metropolitana, ao mesmo tempo em que pode estar se referindo à cultura política de distintas culturas, como a das regiões metropolitanas brasileiras.

Do ponto de vista da cultura política, o recorte institucional, político e administrativo iniciado na década de 1970, reformulado no período de abertura democrática e que vem passando por novas transformações (ROCHA \& FARIA, 2010) é o espaço de coexistência de vários padrões de cultura cívica, entendidas aqui, minimamente, como combinações de cultura paroquial, súdita e participativa. Contudo, essas formas de articulação de diferentes culturas, possivelmente caleidoscópicas, ainda têm sido pouco contempladas, salvo os estudos recentes desenvolvidos pelo Observatório das Metrópoles ${ }^{6}$, no bojo de uma análise crítica do paradigma da Nova Cultura Política ${ }^{7}$.

A título de ilustração, pode-se imaginar uma situação corriqueira, ao tomar um táxi numa Região Metropolitada com destino a uma confraternização entre amigos numa cidade vizinha. Em conversa informal com o taxista, ele comenta: "'eles' agora não querem mais deixar a gente passar por esse caminho". Nesse caso, "eles", pode ser uma referência ao poder público em geral, à polícia, à prefeitura, a um proprietário ou a qualquer instância que seja capaz de impor sua vontade. Antes de chegar ao destino, suponhamos uma parada para ir aos correios e, na fila, em conversa com um cidadão que mira um casal pobre, com filhos, numa fila ao lado, ele diz: "eles' agora estão exigindo a matrícula dos filhos na escola para pagar a bolsa". Através desse exemplo grotesco e quase caricatural de um possível "paroquialismo", o que procuramos apresentar é uma indiferenciação da autoridade - "eles", aqui, pode significar o Estado, a União, a Prefeitura, a polícia, o juiz, o padre, o chefe religioso. A menos de meio quilômetro dali, na confraternização, já se encontra um ambiente pluralista 
compatível com os padrões da NCP: estão presentes um corretor de imóveis que busca imóveis antigos para comprar e demolir na região, uma feminista que luta pelo direito ao aborto, um militante local que defende a preservação da mata ciliar dos córregos da região, uma advogada que acabou de defender o conhecido mandante de um crime contra delegados do trabalho, um estudante de psicologia militante da causa antimanicomial. Todos eles estão reunidos em torno de uma audição de chorinho. Aqui se tem o quadro de uma cultura pluralista, de lealdades entrecruzadas, em que cada um compete por suas preferências. Como essas pessoas se articulam? Elas poderiam participar de uma ação coletiva em benefício do time de futebol recém formado na região? Quais delas apostariam seu tempo na formação de uma associação para impedir as queimadas? Quais participariam do Orçamento Participativo Digital? Quantas delas têm filiação partidária? Quais delas preferirão resolver problemas que as afetam através de contato com um político influente?

O espectro de atitudes que envolvem crenças, afeto e julgamento está aqui, em alguma medida, contextualizado no espaço da região metropolitana. Quanto àqueles cidadãos de baixa renda e pouco informados, em que momento são cidadãos metropolitanos? Na vivência do transporte coletivo, no abastecimento, na procura do tratamento médico?

O que aqui se ressalta é a ampla possibilidade de articulações de culturas e subculturas políticas no espaço metropolitano. Daí a necessidade de se identificar que tipo de Nova Cultura Política (NCP), pode estar ocorrendo nas regiões metropolitanas brasileiras. Existiria uma NCP com padrões distintos daqueles concebidos por teóricos como Inglehart e Clark? Em que sentido esses padrões seriam distintos e em que aspectos poderiam ser considerados semelhantes?

Para prosseguir a discussão, tomemos os sete pontos definidos por Clark para pensá-los no espaço de uma hipotética região metropolitana brasileira. Quanto ao aspecto da redefinição do contínuo direita e esquerda, diferentemente do que ocorre nos países europeus, esse contínuo não tem tido, no Brasil, ao longo de sua história republicana, um delineamento muito claro. Em que momento da história brasileira ele esteve presente? Supostamente, a partir da fundação do Partido dos Trabalhadores (PT), no início da transição à democracia, embora a esquerda já existisse antes - em 1922 havia sido criado o Partido Comunista, que viveu a maior parte do tempo na clandestinidade e nunca chegou a ter um movimento de massas que o apoiasse. No período democrático ocorrido entre 1945 e 1964, a esquerda chegou a participar da política de massas como parte de uma coligação, no período populista, sem ter grande visibilidade como partido. Por outro lado o PT - que hoje tem um perfil mais claro que aquele da esquerda dos períodos anteriores no país - já não defende bandeiras tão à esquerda como em seu início. Uma das explicações possíveis seria o 
fato de o partido ter chegado ao poder e se tornar sujeito à inexorável tendência à burocratização e separação de suas bases, consagrada na análise de Michels (1966) como "a lei de ferro da oligarquia". Por outro lado, não se deve ignorar o reordenamento mundial do Ocidente, após a queda do Muro de Berlim e o final da Guerra Fria. O que aqui se afirma é que o recorte, esquerda e direita, visível nos países europeus, especialmente os de democracia consolidada a partir do século XIX e até quase final de XX, nunca se efetivou no Brasil da mesma maneira. A luta dos trabalhadores no Brasil esteve longe do padrão que ocorreu em países como França, Inglaterra e Itália, no que se refere especialmente à identidade partidária. Assim, pouco se adequaria o conceito de Nova Cultura Política (NCP), quando se trata de entender e explicar as mudanças no contínuo tradicional, esquerda e direita. Esse contínuo, sendo claro nos dias de hoje, não o foi no período anterior, iniciado a partir da Revolução Industrial. O que aqui se quer realçar é que a ideia de ruptura com a "velha cultura política" só se aplica no Brasil com algum cuidado, pois a cultura política anterior à NCP não era exatamente como a dos países onde o conceito foi cunhado.

Relativamente à separação de questões sociais e financeiras, entende-se que as atitudes pertinentes aos temas sociais não são derivadas das atitudes relacionadas às questões financeiras. Seria o caso das mobilizações por temas relacionados a questões de gênero, meio ambiente, valores de convivência, temas chamados por Inglehart (1997) de "pós-materialistas"? Nesse espectro, as novas lealdades se entrecruzam de forma que as associações podem atravessar as lealdades de classes de maneira diferente das solidariedades de classe convencionais. Por exemplo, uma ONG que defende a recuperação de um determinado rio e de sua bacia, pode congregar pessoas de diferentes classes sociais, raças, níveis de renda, tipos e lugar de residência.

Na Nova Cultura Política os problemas sociais passaram a ser muito mais importantes que os problemas econômicos e financeiros. Mobilizações pela defesa da sociabilidade urbana - como uma determinada "cultura de praia", a "lei do silêncio" ou a "civilidade no trânsito" - poderiam indicar a ênfase em valores sociais, típicos da metrópole. No caso do Brasil, sua existência indica algo novo, mas isso não significa necessariamente que os problemas que envolvem renda, moradia, saneamento ou transporte tenham perdido importância (AZEVEDO, SANTOS JUNIOR \& RIBEIRO, 2009).

Outro dos aspectos realçados por Clark (2002), provavelmente baseado em seus estudos sobre a cultura política em Chicago, é a ascensão do mercado e do individualismo social. Ao mesmo tempo em que aumenta a participação e o compromisso por causas sociais de forma distinta das questões de classe, cresce o individualismo social expressado nos partidos que advogam o liberalismo econômico. Segundo Azevedo, Santos Junior e Ribeiro (2010), essa 
tendência também estaria ocorrendo no Brasil, "no fortalecimento de partidos e líderes que associam o liberalismo ao progressismo social".

Quanto ao questionamento do Estado de Bem-Estar, que tem sido considerado um ingrediente característico da nova forma de avaliar e julgar a política, a situação no Brasil é bem mais complexa que nos países de capitalismo central. Os movimentos sociais urbanos, desde que puderam existir - a partir da segunda metade da década de 1970, período que corresponde à fase de desgaste da ditadura -, têm reclamado sempre a efetivação do Estado de Bem-Estar. Num país com um dos maiores níveis de desigualdade do planeta, isso é facilmente explicável. Espera-se do Estado o papel de garantidor dos padrões de saúde, habitação e segurança dos quais ele anteriormente se eximiu, situação que a dinâmica do setor privado aprofundou ao longo dos anos. Seria, pois, difícil criticar o Estado de Bem-Estar onde ele ainda não se efetivou - embora alguns setores vejam com apreensão medidas de proteção social conduzidas pelo Estado que, comparadas com os padrões de bem-estar atingidos por países europeus, podem ser consideradas tímidas. É o caso de críticos do governo Lula, que têm como um de seus alvos o ensaio de distribuição de renda representado pelo Programa Bolsa-Família - embora essas críticas tenham se abrandado no período eleitoral.

Se, nos países centrais, especialmente em suas metrópoles, as questões políticas e a expansão da participação cidadã estão se expandindo pari passu com o declínio da importância das organizações políticas hierárquicas, como partidos e sindicatos, no Brasil se contraria essa tendência mundial. Provavelmente devido à importância do Partido dos Trabalhadores no poder, os representantes sindicais nunca ocuparam tantos cargos e nunca tiveram tanto espaço no governo. As pesquisas do Instituto de Pesquisa e Planejamento Urbano e Regional , IPPUR, apontam a tendência predominante da "automobilização" no estudo das seis metrópoles brasileiras ${ }^{8}$.

As orientações da Nova Cultura Política estariam, ainda, mais difundidas entre os jovens nas sociedades mais formalmente educadas e afluentes. No Brasil, as regiões metropolitanas congregam cerca de $43 \%$ da população brasileira. Embora, indiscutivelmente, seja nelas que se concentra a maior riqueza do país, é nelas também que se encontram os maiores focos de pobreza. Isso torna a questão ainda mais delicada. As camadas mais afluentes do Brasil não têm tido, ao longo de sua história, preocupação com a questão da pobreza e da exclusão, não considerando a sociedade como um sistema integrado, como fez a classe dominante inglesa. Esta, ao final da era vitoriana, diante do crescimento da exclusão e da indigência, tratou o tema como uma questão do país, no contexto de um debate público, no qual se envolveram demógrafos, estatísticos, sanitaristas, humanistas e escritores (SOUKI, 2006). Embora, recentemente, se perceba, entre certos setores empresariais, alguma ideia de interdependência da sociedade,
8. Os dados mais recentes sobre a aplicação do conceito de Nova Cultura Política (NCP) estão em Azevedo, Ribeiro e Santos Júnior (orgs.) (2012), obtidos em uma pesquisa comparada em seis metrópoles brasileiras. 
o que se reflete em preocupação com a questão da pobreza como um problema do país (REIS, 2000), seria prematuro, contudo, afirmar que isso signifique necessariamente um novo padrão cultural. O que aqui se coloca é o fato de a atuação das classes afluentes no Brasil, e suas elites, não ter apresentado, ao longo de sua história, um sentido de responsabilidade social, mesmo que conservador, capaz de fortalecer a tese de participação da NCP. Quanto ao comportamento de setores mais jovens, a pesquisa de Azevedo, Santos Junior e Ribeiro (2010) não fornece elementos para conclusões a respeito.

Isso posto, o que aqui se realça é que, havendo uma NCP no espaço metropolitano no Brasil, ainda que ela compartilhe semelhanças com o modelo de Clark, não se deve perder de vista que o Brasil não viveu, com a mesma intensidade e coerência, a velha cultura política sobre a qual se cunhou o novo conceito. Sendo um país de democracia recente, em que convivem padrões quase insustentáveis de desigualdade, as questões econômicas atravessam os problemas sociais de maneira a pouco se adequarem a certas tendências descritas na NCP. Nesse quadro, o recorte institucional metropolitano no Brasil apresenta singularidades que fazem com que nem sempre o termo "região metropolitana" possa ser usado no mesmo sentido em que se usa o termo "metropolitano" para Chicago, Nova Iorque, Los Angeles, Londres, Berlim ou Lisboa. Finalmente, e talvez o mais instigante a ser pesquisado, é o fato de a cultura política metropolitana conter uma variedade de padrões de cultura política surpreendente entre si e, especialmente, no interior da própria região metropolitana.

Abstract: The aim of this paper is to examine the articulations of the traditional political culture, understood as "civic culture", and of the "New Political Culture" (NPC), while cohabiting the same metropolitan area. The central question is whether it makes sense, in a country, like Brazil, with little time of existing democracy, to develop a concept to capture the NCP that is adapted to our idiosyncrasies. This effort will involve a theoretical and methodological discussion on the concept of political culture, as well as a discussion on the adequacy of new design of the NCP to a metropolitan culture of recent democratic tradition.

Keywords: Civic Culture, New Political Culture, Metropolis, Recent Democracy, Metropolitan Culture.

\section{Referências}

ALMOND, G.; VERBA, S. The Civic Culture. Princeton: Princeton University Press, 1963. 
. The Civic Culture Revisited. Newbury Park. California: Sage Publications, 1989.

AZEVEDO, S.; SANTOS Jr, O., RIBEIRO, L. C. Q. "Mudanças e permanências na cultura política das metrópoles brasileiras". Dados, vol. 52, n 3, 2010.

. "Metrópoles, cultura política e cidadania no Brasil". Cadernos Metrópole, v. 11, no 22, 2009.

. (orgs) Cultura Política, Cidadania e Voto: desafios para a governança metropolitana. Rio de Janeiro: Letra Capital, 2012.

AZEVEDO, S.; MARES GUIA, V. “Os 'dois lados da moeda' nas Propostas de Gestão Metropolitana: virtude e fragilidade das políticas", In: E. Castro e M. Wojciechowski (orgs.), Inclusão, colaboração e governança urbana. Belo Horizonte: Ed. Puc-Minas/The University British Columbia, 2010, p. 65-100.

. "Efeito metrópole e cultura política: novas modalidades de exercício da cidadania na metrópole de Lisboa". Rio de Janeiro: Cadernos Metrópole, v. $11, \mathrm{n}$ ㅇ 22, 2009.

- "O exercício da cidadania política em perspectiva histórica (Portugal e Brasil)". RBCS, vol. 18, no 51, 2003.

CARVALHO, J. M. “Cidadania: tipos e percursos". Estudos Históricos, no 18, 1996, p. 337-359.

CLARK, T. et al. "Amenitys Drive Urban Growth". Journal of Urban Affairs, vol. 24, no 5, 2002, p. 493-515.

DAHL, R. La poliarquía: participación y oposición. Madrid: Tecnos, 1989.

FERES JUNIOR, J.; EISENBERG, J. “Dormindo com o Inimigo: Uma Crítica ao Conceito de Confiança". Dados, vol. 49, no 3, 2006.

INGLEHART, R. The Silent Revolution: Changing Values and Political Styles Among Western Publics. Princeton: Princeton University Press, 1977.

. Modernization and Posmodernization: Cultural, Economic, and Political Change in Forth-Three Societies. Princeton: Princeton University Press, 1997.

JOHNSON, J. "Problemas Conceituais como Obstáculos ao Progresso em Ciência Política. Quatro Décadas de Pesquisa em Cultura Política". Teoria \& Sociedade, no 12, 2004. 
LESSA, R. "A teoria da democracia: balançose perspectivas", In: R. Perissinottoe M. Fuks (orgs.). Democracia, Teoria e Prática. Rio de Janeiro: Relume Dumará, 2002.

LIJPHART, A. Modelos de Democracia: desempenho e padrões de governo em 36 países. Rio de Janeiro: Civilização Brasileira, 2003.

MACHADO, G. G. Gestão metropolitana e autonomia municipal. Belo Horizonte: Observatório das Metrópoles/Ed. Puc-Minas, 2009.

MARAVALL, J. M. "Democracia y Democratas". Estudios, no 65. Madrid, Instituto Juan March de Estúdios y Investigacones, 1995.

MICHELS, R. Los Partidos Políticos II. Um estúdio sociológico de las tendencias oligárquicas de la democracia moderna. Buenos Aires: Amorrortu, 2003.

MEYEnBERG, Y. L. "Cultura Política. El trayecto de um concepto". ALARCON, V. (Coord.), Metodologias para el analisis político. México: UAMI, Plaza y Valdés, 2006

NUNES, E. A Gramática Política do Brasil. Rio de Janeiro: Zahar, 1999.

O'DONNEL, G. "Transições, continuidades e alguns paradoxos", In: F. W. Reis e G. O’Donnel (orgs.). A democracia no Brasil. Dilemas e perspectivas. São Paulo: Vértice, 1988, p. 41-71.

PRZEWORSKI, A., CHEIBUB, J. A.; LIMONGI, F. "Democracia e Cultura: uma Visão Não Culturalista". Lua Nova, no 58, 2003.

PUTNAM, R. Comunidade e Democracia: a experiência da Itália moderna. Rio de Janeiro, Fundação Getúlio Vargas, 1996.

REIS, B. W. "Capital Social e Confiança: Questões de Teoria e Método". Revista de Sociologia e Política, vol. 21, 2003.

REIS, E. P. "Percepções das elites sobre pobreza e desigualdade". RBCS, v.15, no 42, 2000, p. 144-152.

ROCHA, C. A.; FARIA, C. A. "Federalismo, relações intergovernamentais e gestão metropolitana no Brasil", In: E. Castro e M. Wojciechowski (orgs.), Inclusão, colaboração e governança urbana. Belo Horizonte: Ed. Puc-Minas/The University British Columbia, 2010, p. 101-119.

SOUKI, L. G. "A atualidade de T. H. Marshall no estudo da cidadania no Brasil". Civitas, v. 6, no 1, 2006, p. 39-58.

WHITEHEAD, L. "Aspectos internacionales de la democratización", In: G. O'Donnell, P. Schmitter e L. Whitehead (orgs.). Transiciones desde un gobierno autoritario. Barcelona: Paidós. Vol. 3, 1988, p. 15-78. 